\title{
Cooperative In-Sn catalyst system for efficient methyl lactate synthesis from biomass-derived sugars
}

Koji Nemoto, ${ }^{\mathrm{a}}$ Yoshiaki Hirano, ${ }^{\mathrm{b}}$ Kei-ichi Hirata, ${ }^{\mathrm{a}}$ Tsukasa Takahashi, ${ }^{\mathrm{b}}$ Hideaki Tsuneki, Ken-ichi Tominaga, ${ }^{\mathrm{a}, \mathrm{d} *}$ and Kazuhiko Sato, ${ }^{\mathrm{a}, \mathrm{d}}$

a Interdisciplinary Research Center for Catalytic Chemistry, National Institute of Advanced Industrial Science and Technology (AIST), 1-1-1 Higashi, Tsukuba, Ibaraki 305-8565, Japan

${ }^{\mathrm{b}}$ Research Planning Division, NIPPON SHOKUBAI CO., LTD., 5-8, Nishi Otabi-cho, Suita, Osaka 564-0034, Japan

${ }^{c}$ Research Division, NIPPON SHOKUBAI CO., LTD., 5-8, Nishi Otabi-cho, Suita, Osaka 5640034, Japan

d Catalysis Research Center, Hokkaido University, Kita21, Nishi10, Kita-ku, Sapporo, Hokkaido, 001-0021, Japan

* Corresponding author:

E-mail: k-tominaga@aist.go.jp; Tel: +81 29-861-8456 


\begin{abstract}
The catalytic conversion of sugars to lactic acid esters holds great advantages over the conventional fermentation process; the reaction is faster and the product can be separated with a simple distillation process. As the conversion of the sugar to the lactic acid ester involves several elemental reactions, multi-component catalyst systems were expected to be effective for this reaction. This paper reports the use of a combination of indium chloride and tin chloride to synergistically catalyze the formation of methyl lactate (MeLac) from sugars in the presence of tetrafluoroborate salts, the maximum yield of which reaches $72 \%$. A plausible reaction scheme is also proposed based on the electrospray ionization mass spectroscopy analyses of the reaction solutions and the effects of the indium species, tin species, and tetrafluoroborate salts on each elemental step from fructose to MeLac.
\end{abstract}

Keywords: Biomass; Lactate; Lewis acid; Synergistic effect; Indium; Tin

\title{
1. Introduction
}

Lignocellulosic biomass is a promising sustainable resource; it is abundant, non-toxic, renewable, and is non-competitive with food. The worldwide production of lignocellulose is estimated at approximately $1.7 \times 10^{11}$ tons/year [1]. Among the chemicals that can be synthesized from lignocellulosic biomass, lactic acid (LacA) is a potential platform because it plays a significant role in prospective biomass-refinery systems such as green solvents, biodegradable polymers, and as precursors of propylene glycol and acrylic acid [2].

The current commercial processes for the production of LacA are mainly based on the fermentation of sugars, and despite high yields, there exist several problems related to the separation of LacA from the broth. Most notably, the separation and purification cost is estimated to be about $50 \%$ of the total production cost $[2(b)]$.

In recent years, much attention has been paid to chemocatalytic LacA or the syntheses of its esters from hexoses, including cellulose, because of the higher reaction rates of these processes compared to those of the fermentation processes [2(c), 2(d), 3]. Alkaline metal salts [4], tin salts [5], 
lanthanide triflates [6], lead salts [7], and solid catalysts, such as zeolite [8], clay [9], and tungsten compounds [10] have been reported to be effective catalysts for these reactions. The conversion of hexoses to LacA occurs via two key steps catalyzed by a Lewis acid: (i) hexose is cleaved to two trioses by a retro-aldol reaction, and this is followed by (ii) the isomerization to LacA (Scheme 1). Two molecules of LacA are formed from one molecule of hexose.

[Scheme 1]

Compared to LacA, its esters, such as MeLac, offer advantages in terms of product separation in that they can be recovered by simple distillation. Although several examples of the catalytic synthesis of MeLac from hexoses have been reported to date, the yields of these reactions $[5,8]$ are generally lower than those of the reactions starting from trioses [11]. Our catalyst design strategy for this reaction is based on the idea that it should be possible to improve each key step in Scheme 1 by using a more efficient catalyst species. Following this strategy, we succeeded in developing an efficient two-component catalyst system for the synthesis of MeLac from hexoses, which is reported herein.

\section{Experimental}

\subsection{General information}

Methanol was purchased from Wako Pure Chemical Industries, Ltd. and used as received without any purification. $\mathrm{BCl}_{3} \cdot \mathrm{SMe}_{2}, \mathrm{TiCl}_{4} \cdot 2 \mathrm{THF}, \mathrm{ZrCl}_{4} \cdot 2 \mathrm{THF}, \mathrm{InF}_{3}, \mathrm{InBr}_{3}, \mathrm{In}(\mathrm{OTf})_{3}, \mathrm{SnBr}_{2}$, and $\mathrm{SnI}_{2}$ were purchased from Sigma-Aldrich Corporation. $\mathrm{GaCl}_{3}, \mathrm{InCl}_{3} \cdot 4 \mathrm{H}_{2} \mathrm{O}, \mathrm{SnCl}_{2} \cdot 2 \mathrm{H}_{2} \mathrm{O}$, $\mathrm{SnCl}_{4} \cdot 5 \mathrm{H}_{2} \mathrm{O}, \mathrm{HfCl}_{4} \cdot 2 \mathrm{THF}, \mathrm{ScCl}_{3} \cdot 6 \mathrm{H}_{2} \mathrm{O}, \mathrm{YCl}_{3} \cdot 6 \mathrm{H}_{2} \mathrm{O}, \mathrm{YbCl}_{3} \cdot 6 \mathrm{H}_{2} \mathrm{O}$, anhydrous $\mathrm{SnCl}_{2}$, and $\mathrm{SnF}_{2}$ were purchased from Wako Pure Chemical Industries, Ltd. Anhydrous $\mathrm{InCl}_{3}$ and $\mathrm{Sn}(\mathrm{OTf})_{2}$ were purchased from Tokyo Chemical Industry. $\mathrm{AlCl}_{3} \cdot 6 \mathrm{H}_{2} \mathrm{O}$ was purchased from KISHIDA Chemical Co., Ltd. Fructose and cellobiose were purchased from KISHIDA Chemical Co., Ltd., glucose and maltose from Wako Pure Chemical Industries, Ltd, and sucrose from Junsei Chemical Co., Ltd. As standards materials for HPLC, MeLac, MeLev, methyl 2-hydroxy-3-butenoate (Me2H3B), $\alpha$ - 
methylglycoside and 2-methyl tetrahydrofuran were purchased from Tokyo Chemical Industry. 5methoxymethyl-2-frufural (MMF) was prepared according to a known procedure [12].

\subsection{General procedure for methyl lactate synthesis}

A $50 \mathrm{~mL}$ stainless-steel autoclave equipped with a magnetic stirring bar was charged with starting material $(2.5 \mathrm{mmol})$, a Lewis acid as the main catalyst $(0.05 \mathrm{mmol})$, and methanol $(20 \mathrm{~mL})$. If necessary, a second Lewis acid $(0.01 \mathrm{mmol})$ and salts $(0.05 \mathrm{mmol})$ were added. Then the apparatus was purged with $\mathrm{N}_{2}$ gas by repeated pressurization and subsequent expansion and the final pressure was adjusted to $0.5 \mathrm{MPa}$. The apparatus was heated to $160{ }^{\circ} \mathrm{C}$ and maintained at this temperature for $10 \mathrm{~h}$ with stirring. After the apparatus was cooled to room temperature, it was depressurized and the reaction solution was recovered.

\subsection{General procedure for HPLC analysis}

The HPLC analyses were carried out on JASCO LC-2000Plus systems with RI and UV-Vis detectors. The quantitative analysis of unreacted sugars was performed by Aminex HPX-87H (250×4.0 mm I.D., Bio-Rad Laboratories, Inc.) using a $7.5 \mathrm{mM}$ aqueous solution of sulfuric acid as

the mobile phase with the column oven at $65^{\circ} \mathrm{C}$ and 2-methyl tetrahydrofuran as internal standard. The quantitative analysis of MeLac, Me2H3B, MMF, and MeLev were performed on a Scherzo SSC18 (250×4.0 mm I.D., Imtakt Corp.) using a 20 vol\% aqueous solution of methanol containing 10 $\mathrm{mM}$ of formic acid as a mobile phase with the column oven at $40{ }^{\circ} \mathrm{C}$ and 2-methyl tetrahydrofuran as internal standard.

\subsection{General procedure for ESI-MS analysis}

A $50 \mathrm{~mL}$ stainless-steal autoclave equipped with a magnetic stirring bar was charged with $\mathrm{InCl}_{3} \cdot 4 \mathrm{H}_{2} \mathrm{O}(0.05 \mathrm{mmol}), \mathrm{SnCl}_{2} \cdot 2 \mathrm{H}_{2} \mathrm{O}(0.01 \mathrm{mmol}), \mathrm{NaBF}_{4}(0.05 \mathrm{mmol})$, and methanol $(20 \mathrm{~mL})$. Then the apparatus was purged with $\mathrm{N}_{2}$ by repeated pressurization and subsequent expansion and the final pressure was adjusted to $0.5 \mathrm{MPa}$. The apparatus was heated to $160{ }^{\circ} \mathrm{C}$ and maintained at the 
temperature for $2 \mathrm{~h}$ with stirring. After the apparatus was cooled to room temperature, it was depressurized, and the reaction solution was recovered and directly introduced into the electrospray ionization mass spectroscopy (ESI-MS) system (Waters ZQ-2000). The needle voltage was $3.5 \mathrm{kV}$, and the cone voltage was $50 \mathrm{~V}$. The spectra of the detected In and Sn species were in good agreement with their calculated isotope distribution spectra, which are included as Supporting Information.

\section{Results and Discussion}

\subsection{Methyl lactate synthesis by using Lewis acid catalysts}

As shown in Scheme 1, one of the key steps in the conversion of fructose to trioses is the retro-aldol reaction. Although Lewis acids are expected to be effective catalysts for this step, strong Lewis acidity may cause the dehydrative cyclization of fructose, an undesirable side reaction, to form MMF, which is an intermediate of the formation of methyl levulinate (MeLev) [13]. Besides, when fructose is isomerized to glucose, its retro-aldol reaction gives erythrose and glycolaldehyde, the former of which is known to be further converted to Me2H3B [8a]. Figure 1 shows the results of the reaction of fructose in methanol using $\mathrm{ScCl}_{3}, \mathrm{YCl}_{3}$, and $\mathrm{YbCl}_{3}$ as group 3 metal chlorides, $\mathrm{TiCl}_{4}$, $\mathrm{ZrCl}_{4}$, and $\mathrm{HfCl}_{4}$ as group 4 metal chlorides, $\mathrm{BCl}_{3}, \mathrm{AlCl}_{3}, \mathrm{GaCl}_{3}$, and $\mathrm{InCl}_{3}$ as group 13 metal chlorides, and $\mathrm{SnCl}_{2}$ and $\mathrm{SnCl}_{4}$ as group 14 metal chlorides as Lewis acid catalysts. In these reactions, major products depended on the metal species; the chloride salts except In and Sn gave MMF as a major product and the chloride salts of In and Sn gave MeLac as a major product. In both cases, a certain amounts of Me2H3B, MeLev, and sugars (glucose and $\alpha$-methylglycoside) were also detected. The material balance shows the presence of unknown compounds, which may be formed by the condensation of glucose or frufural compounds [14]. The most effective chloride salt for the formation of MeLac was $\mathrm{InCl}_{3}$, which produced this compound in a yield of $49 \%$ together with Me2H3B in the yield of $11 \%$, MMF in the yield of $14 \%$, MeLev in the yield of $5 \%$, and sugars in the yield of $4 \%$. 
[Fig. 1]

Another key step in Scheme 1 is the isomerization of trioses to LacA. The catalytic activity of In salts toward the retro-aldol reaction of fructose and the isomerization of trioses was investigated by comparing the synthesis of MeLac from fructose and dihydroxyacetone (DHA). The results are shown in Fig. 2. Noteworthy, there is a trade-off between the yield of MeLac from fructose and that from DHA: the yield of MeLac from fructose increases as the yield of MeLac from DHA decreases. Although the order of Lewis acidities of In halides has not yet been clarified [15], the catalytic activity for the isomerization of DHA appears to depend on the Lewis acidity of the catalyst $\left(\operatorname{In}(\operatorname{acac})_{3}<\operatorname{In}\right.$ halides $\left.<\operatorname{In}(\mathrm{OTf})_{3}\right)$, such that the most effective catalyst among the In compounds shown in Fig. 2 is $\operatorname{In}(\mathrm{OTf})_{3}$, which is the most acidic of the Lewis acids. In other words, the yield of MeLac from DHA reaches $87 \%$, whereas that from fructose is only $8 \%$ because of the side reaction caused by the strong Lewis acidity.

[Fig. 2]

Subsequently, because $\mathrm{SnCl}_{2}$ was found to be the second most effective catalyst for the conversion of fructose to MeLac (Fig. 1), we investigated the catalytic activity of Sn salts toward the retro-aldol reaction of fructose and the isomerization of DHA (Fig. 3). It is noteworthy that, when Sn salts are used as catalysts, there is neither a trade-off between the yield of MeLac from fructose and that from DHA, nor any dependence of the catalyst activity on the Lewis acidity. Among the Sn salts that were tested, $\mathrm{SnCl}_{2}$ was the most effective not only for the conversion of fructose but also for the conversion of DHA.

[Fig. 3]

The catalytic activity toward the retro-aldol reaction was evaluated by introducing a pseudoyield of the retro-aldol reaction based on the yield of MeLac from fructose and DHA as eq. 1, because this reaction proceeds successively.

[Equation 1]

The effects of $\mathrm{InCl}_{3}$ and $\mathrm{SnCl}_{2}$ on the retro-aldol reaction of fructose and the isomerization of DHA are summarized in Table 1. Clearly, these two salts have different catalytic activities: the former 
exhibits higher catalytic activity toward the retro-aldol reaction of fructose, whereas the latter shows higher catalytic activity toward the isomerization of DHA.

[Table 1]

\subsection{Methyl lactate synthesis using In-Sn catalyst systems}

The above results led us to the idea that the combination of In and Sn salts would improve the efficiency of the synthesis of MeLac from fructose. The results are shown in Fig. 4. Contrary to our expectations, in the absence of any additive salts, the combined use of $\mathrm{InCl}_{3}$ and $\mathrm{SnCl}_{2}$ showed no positive effect on the formation of MeLac (48\%) even though the yield of MeLev slightly increased (12\%) compared with the use of $\mathrm{InCl}_{3}$ or $\mathrm{SnCl}_{2}$ alone. Because the total yield of MMF and MeLev were little changed, the addition of $\mathrm{SnCl}_{2}$ to $\mathrm{InCl}_{3}$ appears to enhance the transformation of MMF to MeLev. Expecting to suppress the formation of MMF, we investigated the effect of an additive salt on this combination. Although the total yield of MMF and MeLev decreased in the presence of $\mathrm{NaCl}, \mathrm{NaBr}$, and $\mathrm{NaI}$, almost no positive effect on the formation of MeLac was observed. In the presence of fluoride salts, however, the yield of MeLac obviously increased compared to the yield obtained by the reaction with $\mathrm{InCl}_{3}$ or $\mathrm{SnCl}_{2}$ alone. The choice of cation for the fluoride salts did not appear to influence the yield. The tetrafluoroborate salts were more effective for the formation of MeLac; when $\mathrm{NaBF}_{4}$ was used, MeLac was formed in the yield of $72 \%$, together with Me2H3B in the yield of $15 \%$, MMF in the yield of $4 \%$, MeLev in the yield of $1 \%$, and sugars in the yield of $2 \%$. On the other hand, the hexafluorophosphate salt had no positive effect on this catalysis, probably because the hexafluorophosphate ion decomposed due to hydrolysis by trace amounts of water, which was either present as contaminant or was formed during the reaction [16].

[Fig. 4]

In the presence of tetrafluoroborate salts, other Sn salts were also found to be effective in combination with $\mathrm{InCl}_{3}$ for this reaction (Table 2). However, from the viewpoint of catalytic activity, there was little difference between the $\mathrm{Sn}(\mathrm{II})$ and $\mathrm{Sn}(\mathrm{IV})$ salts.

[Table 2] 
Figure 5 shows the time course of this reaction using the $\mathrm{InCl}_{3} / \mathrm{SnCl}_{2} / \mathrm{NaBF}_{4}$ catalyst system. The formation of MeLac was almost completed within $2 \mathrm{~h}$, beyond which little increase in its yield was observed.

[Fig. 5]

The effects of the reaction temperature are shown in Fig. 6. Only a small amount of MeLac was formed at $120{ }^{\circ} \mathrm{C}$, whereas its yield drastically increased at $140{ }^{\circ} \mathrm{C}$. The optimum temperature was in the range $160-170{ }^{\circ} \mathrm{C}$, beyond which its yield gradually decreased.

[Fig. 6]

The effects of the $\mathrm{In} /(\mathrm{In}+\mathrm{Sn})$ ratio on the yield of MeLac is shown in Fig. 7, which clearly shows a synergistic effect of both of these species [17]. The yield of MeLac increases as the substitution of In species with $\mathrm{Sn}$ species increases. The optimum $\mathrm{In} /(\mathrm{In}+\mathrm{Sn})$ ratio was determined to be approximately from 0.7 to 0.8 , beyond which the yield of MeLac was observed to decrease.

[Fig. 7]

The effects of the catalyst concentration were investigated with the $\operatorname{In} /(\operatorname{In}+\mathrm{Sn})$ ratio being kept consrant at 0.83 (Fig. 8). Although the yield of MeLac decresed with a decrease in the catalyst concentration, the catalyst turnover number (TON) to MeLac formation increased over 2580 . The optimum catalyst concentration for the MeLac formation was about $3 \mathrm{mmol} / \mathrm{L}$, over which its yield gradually decreased with a decrease in TON.

[Fig. 8]

\subsection{Role of $\mathrm{NaBF}_{4}$ in In-Sn catalyst system}

In order to elucidate the effects of tetrafluoroborate salts on this two-component catalysis, the catalyst species were investigated by conducting ESI-MS analyses. As a representative catalyst system, $\mathrm{InCl}_{3} \cdot 4 \mathrm{H}_{2} \mathrm{O}, \mathrm{Bu}_{2} \mathrm{SnCl}_{2}$, and $\mathrm{NaBF}_{4}$ in methanol were heated at $160{ }^{\circ} \mathrm{C}$ for $2 \mathrm{~h}$, and the reaction mixture was analyzed with an ESI-MS apparatus in the positive mode. For comparison, a solution in which $\mathrm{NaCl}$ was used in place of $\mathrm{NaBF}_{4}$ was analyzed by the same method. 
The ESI-MS spectra of these reaction solutions are quite different (Fig. 9). In the presence of $\mathrm{NaBF}_{4}$, the corresponding peak groups of only $[\mathrm{BuSn}]^{+}(\mathrm{a}),\left[\mathrm{InCl}_{2}\right]^{+}(\mathrm{b})$ and tin halide species such as $\mathrm{Na}\left[\mathrm{SnCl}_{2}\right]^{+}(\mathrm{c}),\left[\mathrm{Bu}_{2} \mathrm{SnF}\right]^{+}(\mathrm{d}),\left[\mathrm{Bu}_{2} \mathrm{SnCl}\right]^{+}$(e) were detected (Fig. 9, top), whereas in the presence of $\mathrm{NaCl}$, the corresponding peak groups of $\left[\mathrm{Bu}_{2} \mathrm{SnH}\right]^{+}(\mathrm{f}),\left[\mathrm{Bu}_{2} \mathrm{Sn}(\mathrm{OMe})\right]^{+}(\mathrm{g}), \mathrm{Na}\left[\mathrm{Bu}_{2} \mathrm{SnCl}(\mathrm{OMe})\right]^{+}(\mathrm{h})$, $\mathrm{Na}\left[\mathrm{Sn}(\mathrm{OMe})_{2} \mathrm{InCl}_{3}\right]^{+} \quad$ (i), $\quad\left[\mathrm{Bu}_{2} \mathrm{Sn}(\mathrm{OMe})_{2} \mathrm{InCl}_{2}\right]^{+} \quad(\mathrm{j}), \quad\left[\mathrm{Bu}_{2} \mathrm{Sn}(\mathrm{OMe})_{2} \mathrm{InCl}_{2}(\mathrm{MeOH})\right]^{+} \quad(\mathrm{k}) \quad$ and $\left[\left(\mathrm{Bu}_{2} \mathrm{SnO}\right)_{2} \mathrm{Bu}_{2} \mathrm{Sn}(\mathrm{OMe})\right]^{+}(\mathrm{l})$ appeared in the place of the tin halide species (Fig. 9, bottom).

[Fig. 9]

The above results clearly show that the $\mathrm{BF}_{4}^{-}$anion effectively suppresses the alcoholysis of the Sn chloride species. According to the hard-soft-acid-base (HSAB) principle [18], Sn compounds are relatively hard acids. Hence, the $\mathrm{Cl}^{-}$anion (a borderline base) coordinating to $\mathrm{Sn}$ could be replaced with $\mathrm{MeOH}$, a hard base, to form Sn alkoxides such as (g), (h), (i), (j), (k), and (l) even in the presence of $\mathrm{NaCl}$. However, the $\mathrm{BF}_{4}^{-}$anion, a hard base [19], could be pentacoordinated with $\mathrm{Sn}$ species [20], and this process may prevent the formation of alkoxides. As a result, in the presence of tetrafluoroborate salts, the In chloride and Sn chloride species may exist independent of each other, and this is responsible for efficient MeLac formation from fructose.

Consequently, the catalytic activity of tin methoxide and tin oxide in the formation of MeLac from DHA was investigated by carrying out a controlled reaction using $\mathrm{Bu}_{2} \mathrm{SnO}$, which is known to form $\mathrm{Bu}_{2} \mathrm{Sn}(\mathrm{OMe})_{2}$ in methanol [21], as the catalyst (eq. 2).

[eq. 2]

The results showed that $\mathrm{Bu}_{2} \mathrm{SnO}$ was not a particularly effective catalyst and that the yield of MeLac was only $22 \%$. Thus, the alcoxylation of Sn species appeared to be responsible for the decrease in the catalytic activity of the In-Sn catalyst system.

\subsection{Scope and limitation of In-Sn catalyst system}

The scope and limitations of this In-Sn catalyst system was investigated using various carbohydrates as substrates (Fig. 10). In the case of fructose, the reaction proceeded in the temperature range from 160 to $200{ }^{\circ} \mathrm{C}$ to produce MeLac in almost the same yields, and even at 
$200{ }^{\circ} \mathrm{C}$, the yield did not increase; instead, it decreased slightly. Starting from glucose, the yield of MeLac was less than when fructose was used, but in this case, the yield increased as the reaction temperature increased, which showed that the isomerization of glucose to fructose is slow with this catalyst system. Thus, the yield of MeLac obtained from sucrose lies between that obtained from fructose and from glucose. In addition, both maltose and cellobiose, respectively, produced a lower yield of MeLac than glucose.

[Fig. 10]

\section{Conclusions}

In this study, we investigated a novel catalytic system for the synthesis of MeLac from biomass-derived sugars and determined that a mixed metal system of In chloride and Sn chloride was capable of catalyzing this reaction effectively especially in the presence of tetrafluoroborate salts. The ESI-MS analyses of the reaction solutions showed the presence of the tetrafluoroborate salts to enable each metal species to exist individually and perform its individual intrinsic role in the catalysis. The controlled reaction experiments supported the following reaction mechanism; (i) the retro-aldol reaction of fructose to trioses, the first step in Scheme 1, was mainly catalyzed by In species, and (ii) the isomerization of trioses to MeLac, the second step in Scheme 1, was mainly catalyzed by Sn species. The synergistic effect of these catalytic species resulted in the efficient formation of MeLac from fructose at a maximum yield of $72 \%$. Studies of the direct catalytic conversion of lignocellulosic biomass into methyl lactate are ongoing.

\section{Acknowledgements}

This work was financially supported by a Grant-in-Aid of the Adaptable \& Seamless Technology Transfer Program through Target-driven R\&D (A-STEP) from the Japan Science and Technology Agency (JST).

\section{References}


[1] A. Wang, T. Zhang, Acc. Chem. Res., 46 (2013) 1377-1386.

[2] For recent reviews, see (a) R. Datta, M. Henry, J. Chem. Technol. Biotechnol., 81 (2006) 11191129; (b) C. S. M. Pereira, V. M. T. M. Silva, A. E. Rodrigues, Green Chem., 13 (2011) 2658-2671.

(c) M. Dusselier, P. V. Wouwe, A. Dewaele, E. Makshina, B. F. Sels, Energy Environ. Sci., 6 (2013) 1415-1442; (d) M. Päivi, S. Irina L., S. Tapio, M. Dmitry Yu, Chem. Rev., 114 (2014) 1909-1971.

[3] For recent papers, see (a) S. M. Coman, M. Verziu, A. Tirsoaga, B. Jurca, C. Teodorescu, V. Kuncser, V. I. Parvulescu, G. Scholz, E. Kemnitz, ACS Catal., 5 (2015) 3013-3026; (b) S. Tolborg, I. Sádaba, C. M. Osmundsen, P. Fristrup, M. S. Holm, E. Taarning, ChemSusChem, 8 (2015) 613617; (c) F.-F. Wang, J. Liu, H. Li, C.-L. Liu, R.-Z. Yang, W.-S. Dong, Green Chem., 17 (2015) 2455-2463; (d) B. Murillo, A. Sánchez, V. Sebastián, C. Casado-Coterillo, O. de la Iglesia, M. P. López-Ram- de-Viu, C. Téllez, J. Coronas, J. Chem. Tech. Biotech., 89 (2014) 1344-1350; (e) X. Lei, F.-F. Wang, C.-L. Liu, R.-Z. Yang, W.-S. Dong, App. Catal. A, 482 (2014) 78-83; (f) F. H. Lv, R. Bi, Y. H. Liu, W. S. Li, X. P. Zhou, Catal. Commun., 49 (2014) 78-81.

[4] (a) A. Onda, T. Ochi, K. Kajiyoshi, K. Yanagisawa, Appl. Catal. A, 343 (2008) 49-54; (b) D. Esposito, M. Antonietti, ChemSusChem, 6 (2013) 989 - 992.

[5] F. Lv, R. Bi, Y. Liu, W. Li, X. Zhou, Catal. Commun., 49 (2014) 78-81.

[6] F. Wang, C. Liu, W. Dong, Green Chem., 15 (2013) 2091-2095.

[7] Y. Wang, W. Deng, B. Wang, Q. Zhang, X. Wan, Z. Tang, Y. Wang, C. Zhu, Z. Cao, G. Wang, H. Wan, Nature Commun., 4 (2013) 1-7.

[8] (a) M. S. Holm, S. Saravanamurugan, E. Taarning, Science, 328 (2010) 602-605; (b) M. S. Holm, Y. J. Pagán-Torres, S. Saravanamurugan, A. Riisager, J. A. Dumesicc, E. Taarning, Green Chem., 14 (2012) 702-706; (c) Q. Guo, F. Fan, E. A. Pidko, W. N. P. van der Graaff, Z. Feng, C. Li, E. J. M. Hensen, ChemSusChem, 6 (2013) 1352-1356.

[9] A. Onda, T. Ochi, K. Kajiyoshi, K. Yanagisawa, Catal. Commun., 9 (2008) 1050-1053.

[10] F. Chambon, F. Rataboul, C. Pinel, A. Cabiac, E. Guillon, N. Essayem, Appl. Catal. B, 105 (2011) 171-181.

[11] Y. Hayashi, Y. Sasaki, Chem. Commun., (2005) 2716-2718. 
[12] H. Zhu, Q. Cao, C. Li, X. Mu, Carbohydrate Res., 346 (2011) 2016-2018.

[13] (a) K. Tominaga, A. Mori, Y. Fukushima, S. Shimada K. Sato, Green Chem., 13 (2011) 810-

812; (b) K. Nemoto, K. Tominaga, K. Sato, Chem. Lett., 43 (2014) 1327-1329.

[14] X. Hu, C.-Z. Li, Green Chem., 13 (2011) 1676-1679.

[15] T. Krahl, E. Kemnitz, J. Fluorine Chem., 127 (2006) 663-678.

[16] J. G. Huddleston, A. E. Visser, W. M. Reichert, H. D. Willauer, G. A. Broker, R. D. Rogers, Green Chem., 3 (2001) 156-164.

[17] V. A. Golodov, J. Res. Inst. Catalysis, Hokkaido Univ., 29 (1981) 49-60.

[18] T. Ho, Chem. Rev., 75 (1975) 1-20.

[19] T. Keumei, T. Umeda, Y. Inoue, H. Kitajima, Bull. Chem. Soc. Jpn., 62 (1989) 89-95.

[20] H. C. Clark, R. J. O’Brien, Inorg. Chem., 2 (1963) 1020-1022.

[21] R. K. Ingham, S. D. Rosenberg, H. Gilman, Chem. Rev., 60 (1960) 459-539. 
Table 1 Comparison of pseudo-yield of retro-aldol reaction ${ }^{\mathrm{a}}$

\begin{tabular}{|c|c|c|c|c|}
\hline \multirow[b]{2}{*}{ Entry } & \multirow[b]{2}{*}{ Catalyst } & \multicolumn{2}{|c|}{ MeLac Yield $(\%)^{b}$} & \multirow{2}{*}{$\begin{array}{l}\text { Pseudo-Yield of } \\
\text { Retro-aldol } \\
\text { Reaction (\%) }\end{array}$} \\
\hline & & $\begin{array}{l}\text { from } \\
\text { fructose }\end{array}$ & $\begin{array}{l}\text { from } \\
\text { dihydroxyacetone }\end{array}$ & \\
\hline 1 & $\mathrm{InCl}_{3} \cdot 4 \mathrm{H}_{2} \mathrm{O}$ & 55 & 61 & 90 \\
\hline 2 & $\mathrm{SnCl}_{2} \cdot 2 \mathrm{H}_{2} \mathrm{O}$ & 48 & 97 & 49 \\
\hline
\end{tabular}


Table 2. In-Sn catalysts for MeLac synthesis from fructose ${ }^{\mathrm{a}}$

\begin{tabular}{llll}
\hline Entry & In salts & Sn salts & $\begin{array}{l}\text { MeLac } \\
\text { Yield }(\%)^{\mathrm{b}}\end{array}$ \\
\hline 1 & $\mathrm{InCl}_{3} \cdot 4 \mathrm{H}_{2} \mathrm{O}$ & $\mathrm{Sn}(\mathrm{OTf})_{2}$ & 67 \\
2 & $\mathrm{InCl}_{3} \cdot 4 \mathrm{H}_{2} \mathrm{O}$ & $\mathrm{SnCl}_{4}$ & 68 \\
3 & $\mathrm{InCl}_{3} \cdot 4 \mathrm{H}_{2} \mathrm{O}$ & $\mathrm{Bu}_{2} \mathrm{SnCl}_{2}$ & 70 \\
4 & $\mathrm{InCl}_{3} \cdot 4 \mathrm{H}_{2} \mathrm{O}$ & $\mathrm{Me}_{2} \mathrm{SnCl}_{2}$ & 66 \\
5 & $\mathrm{InCl}_{3} \cdot 4 \mathrm{H}_{2} \mathrm{O}$ & $\mathrm{Bu}_{2} \mathrm{Sn}(\mathrm{OTf})_{2}$ & 64 \\
6 & $\mathrm{InCl}_{3} \cdot 4 \mathrm{H}_{2} \mathrm{O}$ & $\mathrm{Bu}_{2} \mathrm{Sn}(\mathrm{OAc})_{2}$ & 61 \\
\hline${ }^{\mathrm{a}}$ Reaction conditions: $\mathrm{InCl}_{3} \cdot 4 \mathrm{H}_{2} \mathrm{O}(0.05 \mathrm{mmol}), \mathrm{Sn} \mathrm{salts}(0.01 \mathrm{mmol}), \mathrm{Bu} \mathrm{NBF}_{4}(0.05 \mathrm{mmol})$, \\
fructose (2.5 mmol), $\mathrm{MeOH}(20.0 \mathrm{~mL}), \mathrm{N}_{2}(0.5 \mathrm{MPa}), 160^{\circ} \mathrm{C}, 10 \mathrm{~h}$. \\
b The yield was calculated based on the molar amount of fructose.
\end{tabular}


Scheme 1

$$
\text { (i) retro-aldol reaction }
$$

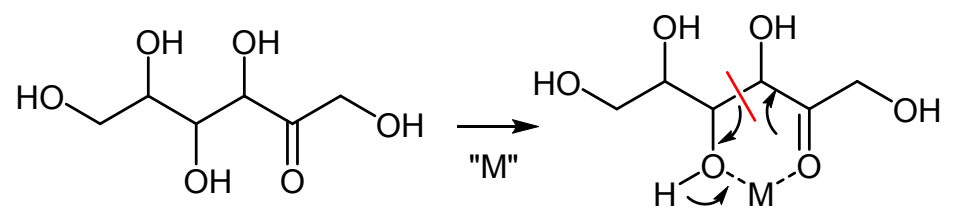

fructose
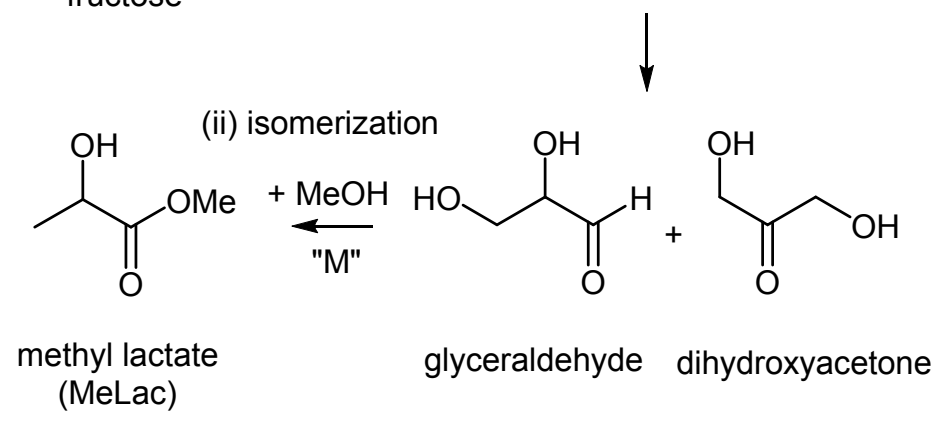
eq. 1

$($ pseudo-yield of retro-aldol reaction $)=$

(yield of MeLac from fructose) / (yield of MeLac from DHA)

eq. 2

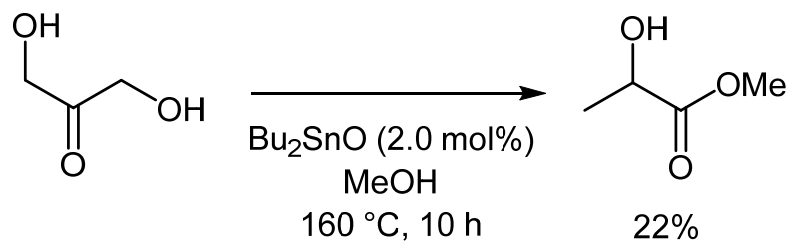




\section{Figure captions}

Fig. 1 MeLac synthesis from fructose catalyzed by various metal chlorides ${ }^{\mathrm{a}}$

${ }^{a}$ Reaction conditions: metal chloride $(0.05 \mathrm{mmol})$, fructose $(2.5 \mathrm{mmol})$, methanol $(20 \mathrm{~mL}), \mathrm{N}_{2}(0.5$ $\mathrm{MPa}), 160{ }^{\circ} \mathrm{C}, 10 \mathrm{~h}$.

Fig. 2 MeLac synthesis from fructose and DHA catalyzed by various In compounds ${ }^{\mathrm{a}}$

${ }^{a}$ Reaction conditions: In compound $(0.05 \mathrm{mmol})$, substrate $(2.5 \mathrm{mmol})$, methanol $(20 \mathrm{~mL}), \mathrm{N}_{2}(0.5$ $\mathrm{MPa}), 160{ }^{\circ} \mathrm{C}, 10 \mathrm{~h}$.

Fig. 3 MeLac synthesis from fructose and DHA catalyzed by various Sn compounds ${ }^{\mathrm{a}}$

${ }^{a}$ Reaction conditions: Sn compound $(0.05 \mathrm{mmol})$, substrate $(2.5 \mathrm{mmol})$, methanol $(20 \mathrm{~mL}), \mathrm{N}_{2}(0.5$ $\mathrm{MPa}), 160{ }^{\circ} \mathrm{C}, 10 \mathrm{~h}$.

Fig. 4 Effects of additive salts on MeLac synthesis catalyzed by In-Sn catalysts ${ }^{\mathrm{a}}$

${ }^{a}$ Reaction conditions: $\mathrm{InCl}_{3} \cdot 4 \mathrm{H}_{2} \mathrm{O}(0.05 \mathrm{mmol}), \mathrm{SnCl}_{2}(0.01 \mathrm{mmol})$, additive salts $(0.05 \mathrm{mmol})$, fructose (2.5 mmol), $\mathrm{MeOH}(20.0 \mathrm{~mL}), \mathrm{N}_{2}(0.5 \mathrm{MPa}), 160{ }^{\circ} \mathrm{C}, 10 \mathrm{~h}$.

Fig. 5 Time course of the formation of MeLac catalyzed by In-Sn catalyst ${ }^{\mathrm{a}}$

${ }^{a}$ Reaction conditions: $\mathrm{InCl}_{3} \cdot 4 \mathrm{H}_{2} \mathrm{O}(0.05 \mathrm{mmol}), \mathrm{SnCl}_{2}(0.01 \mathrm{mmol}), \mathrm{NaBF}_{4}(0.05 \mathrm{mmol})$, fructose (2.5 mmol), $\mathrm{MeOH}(20.0 \mathrm{~mL}), \mathrm{N}_{2}(0.5 \mathrm{MPa}), 160^{\circ} \mathrm{C}$.

$\boldsymbol{\nabla}=$ MeLac, $\square=$ Me2H3B, $\triangle=$ MMF, $\boldsymbol{\Delta}=$ MeLev, $\mathbf{\square}=$ sugars, and $\diamond=$ conversion.

Fig. 6 Effects of reaction temperatures on the formation of MeLac catalyzed by an In-Sn catalyst ${ }^{\mathrm{a}}$ ${ }^{a}$ Reaction conditions: $\mathrm{InCl}_{3} \cdot 4 \mathrm{H}_{2} \mathrm{O}(0.05 \mathrm{mmol}), \mathrm{SnCl}_{2}(0.01 \mathrm{mmol}), \mathrm{NaBF}_{4}(0.05 \mathrm{mmol})$, fructose (2.5 mmol), $\mathrm{MeOH}(20.0 \mathrm{~mL}), \mathrm{N}_{2}(0.5 \mathrm{MPa}), 10 \mathrm{~h}$.

$\boldsymbol{0}=$ MeLac, $\square=$ Me2H3B, $\triangle=$ MMF, $\boldsymbol{\Delta}=$ MeLev, $\mathbf{\square}=$ sugars, and $\bullet=$ conversion. 
Fig. 7 Effects of $\mathrm{In} / \mathrm{Sn}$ ratio on the formation of MeLac catalyzed by In-Sn catalyst $\mathrm{t}^{\mathrm{a}}$

${ }^{a}$ Reaction conditions: $\mathrm{InCl}_{3} \cdot 4 \mathrm{H}_{2} \mathrm{O}, \mathrm{SnCl}_{2}$ (total amount of $\mathrm{In}$ and $\mathrm{Sn}$ is $\left.0.06 \mathrm{mmol}\right), \mathrm{Bu}_{4} \mathrm{NBF}_{4}(0.05$ mmol), fructose $(2.5 \mathrm{mmol}), \mathrm{MeOH}(20.0 \mathrm{~mL}), \mathrm{N}_{2}(0.5 \mathrm{MPa}), 160{ }^{\circ} \mathrm{C}, 10 \mathrm{~h}$.

$\boldsymbol{0}=$ MeLac, $\square=$ Me2H3B, $\triangle=$ MMF, $\boldsymbol{\Delta}=$ MeLev, $\boldsymbol{\square}=$ sugars, and $\diamond=$ conversion

Fig. 8 Effects of catalyst concentration on the formation of MeLac

${ }^{a}$ Reaction conditions: $\mathrm{InCl}_{3} \cdot 4 \mathrm{H}_{2} \mathrm{O}, \mathrm{SnCl}_{2}(\mathrm{In} /(\mathrm{In}+\mathrm{Sn})$ is kept constant at 0.83$), \mathrm{Bu}_{4} \mathrm{NBF}_{4}$ (equimolar amount of In), fructose (2.5 mmol), $\mathrm{MeOH}(20.0 \mathrm{~mL}), \mathrm{N}_{2}(0.5 \mathrm{MPa}), 160{ }^{\circ} \mathrm{C}, 10 \mathrm{~h}$.

$\boldsymbol{\wp}=$ MeLac, $\square=$ Me2H3B, $\triangle=$ MMF, $\boldsymbol{\Delta}=$ MeLev, $\mathbf{\square}=$ sugars, $\diamond=$ conversion, and $\bigcirc=$ TON

Fig. 9 ESI-MS spectra of the reaction solutions in the presence of $\mathrm{NaBF}_{4}$ (top) and in the presence of $\mathrm{NaCl}$ (bottom) $)^{\mathrm{a}}$

${ }^{a}$ Reaction conditions: $\mathrm{InCl}_{3} \cdot 4 \mathrm{H}_{2} \mathrm{O}(0.05 \mathrm{mmol}), \mathrm{Bu}_{2} \mathrm{SnCl}_{2}(0.01 \mathrm{mmol})$, salt $(0.05 \mathrm{mmol}), \mathrm{MeOH}$ (20.0 mL), $\mathrm{N}_{2}(0.5 \mathrm{MPa}), 160^{\circ} \mathrm{C}, 2 \mathrm{~h}$.

Fig. 10 MeLac synthesis from various kinds of sugars catalyzed by In-Sn catalyst ${ }^{\mathrm{a}}$

a Reaction conditions: $\mathrm{InCl}_{3} \cdot 4 \mathrm{H}_{2} \mathrm{O}(0.05 \mathrm{mmol}), \mathrm{SnCl}_{2}$ (0.01 mmol), $\mathrm{NaBF}_{4}$ (0.05 mmol), sugar (2.5

mmol as a monosaccharides), $\mathrm{MeOH}(20.0 \mathrm{~mL}), \mathrm{N}_{2}(0.5 \mathrm{MPa}), 10 \mathrm{~h}$. 
Fig. 1

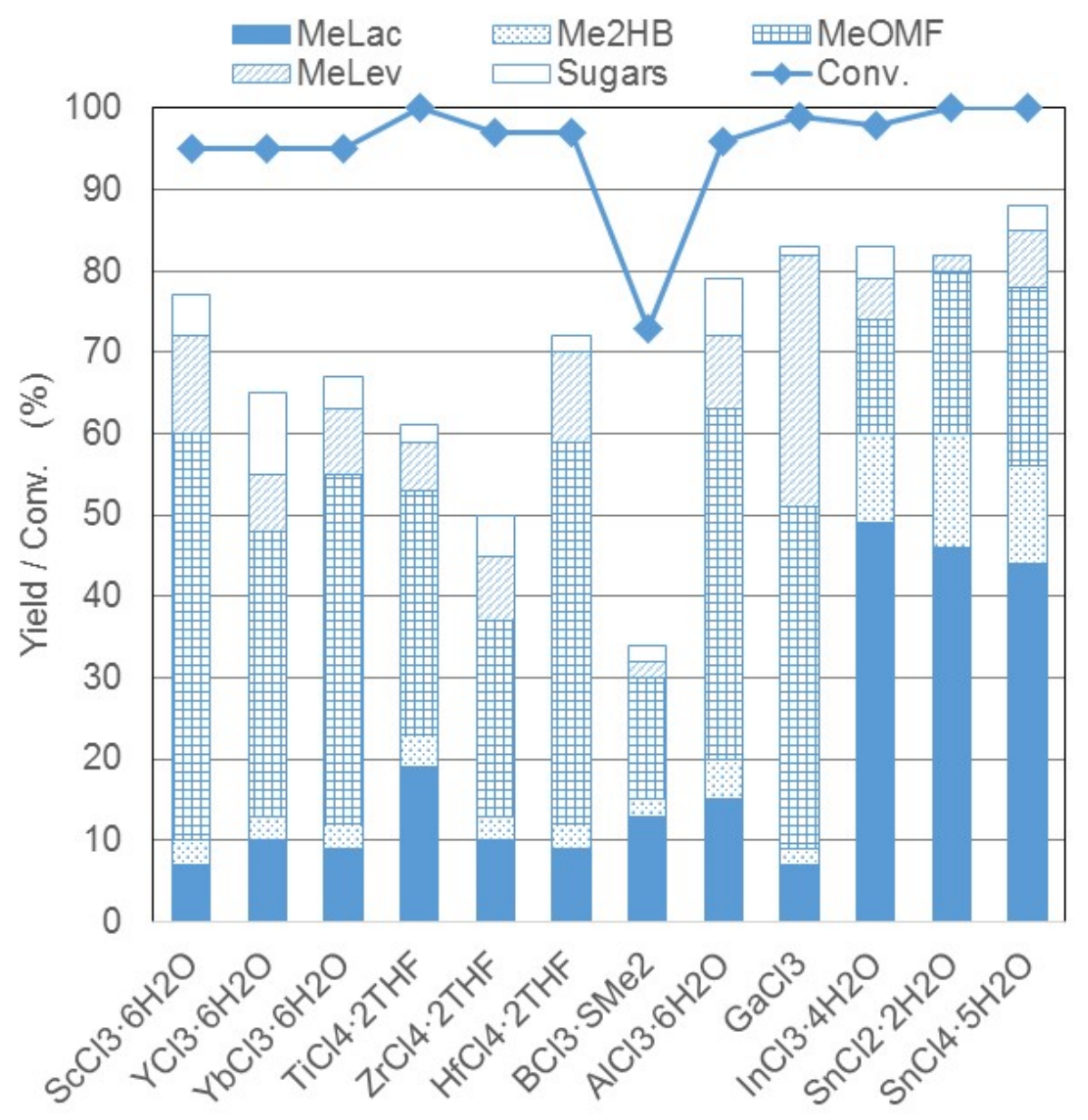


Fig.2

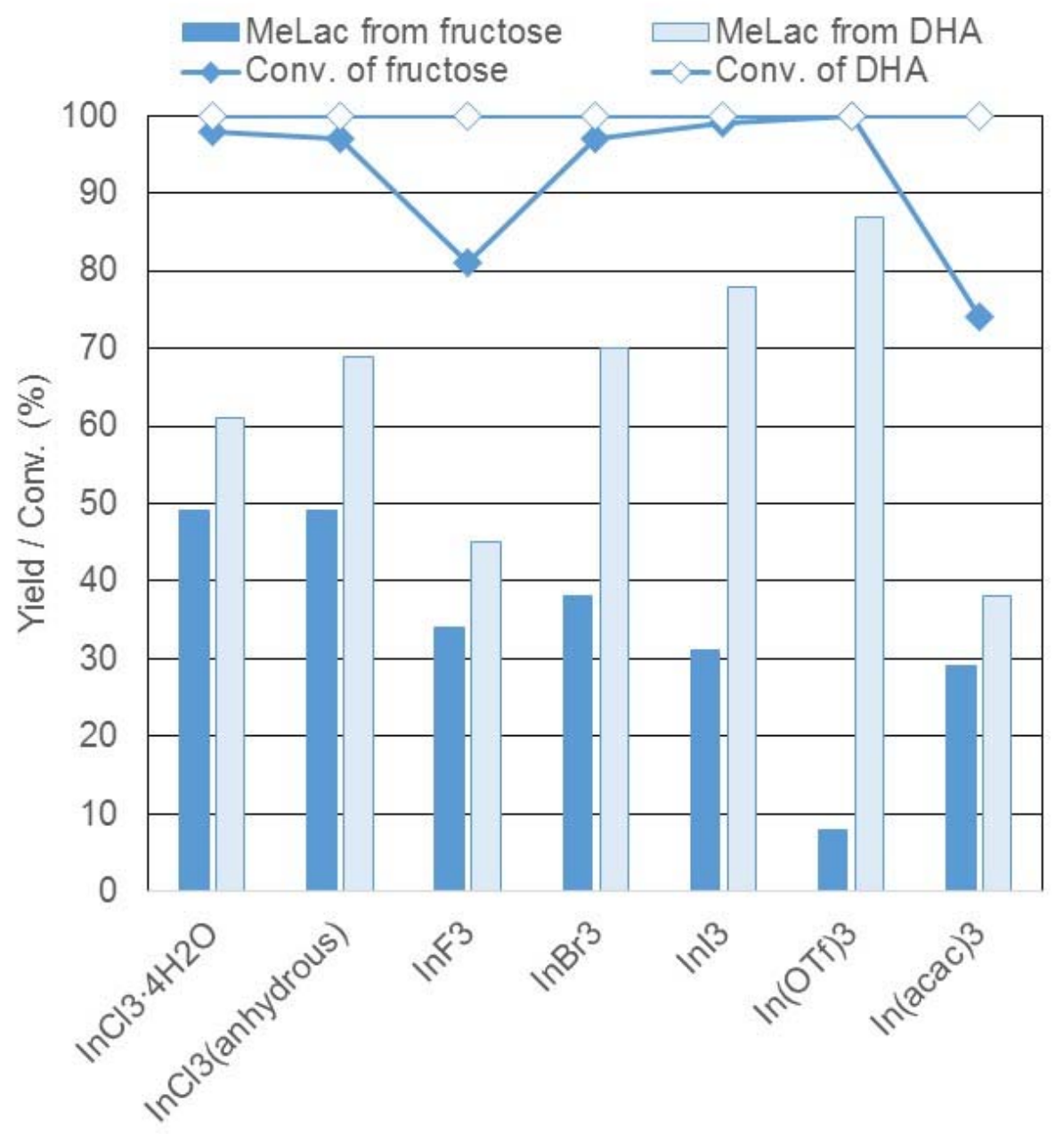


Fig.3

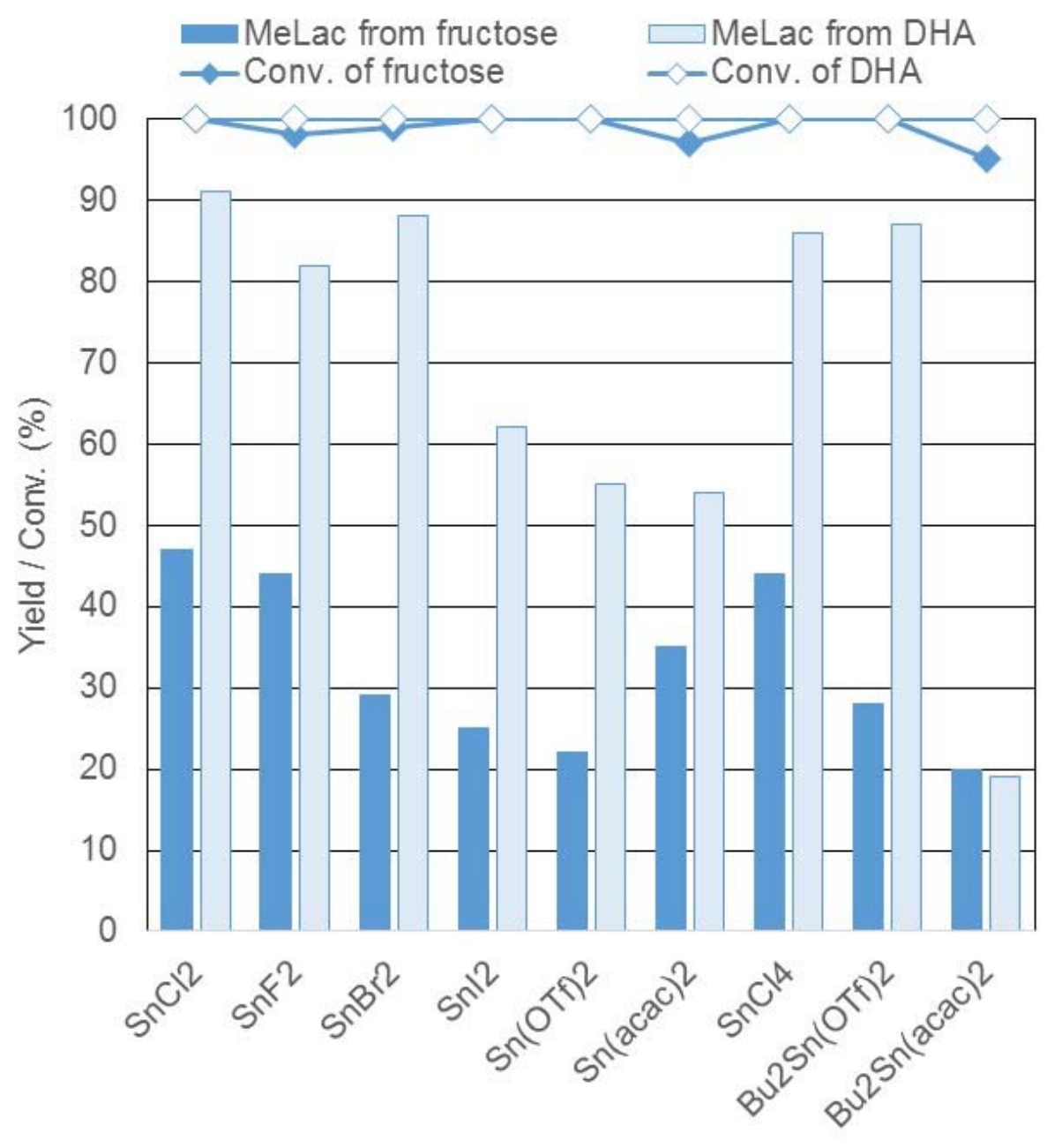


Fig.4

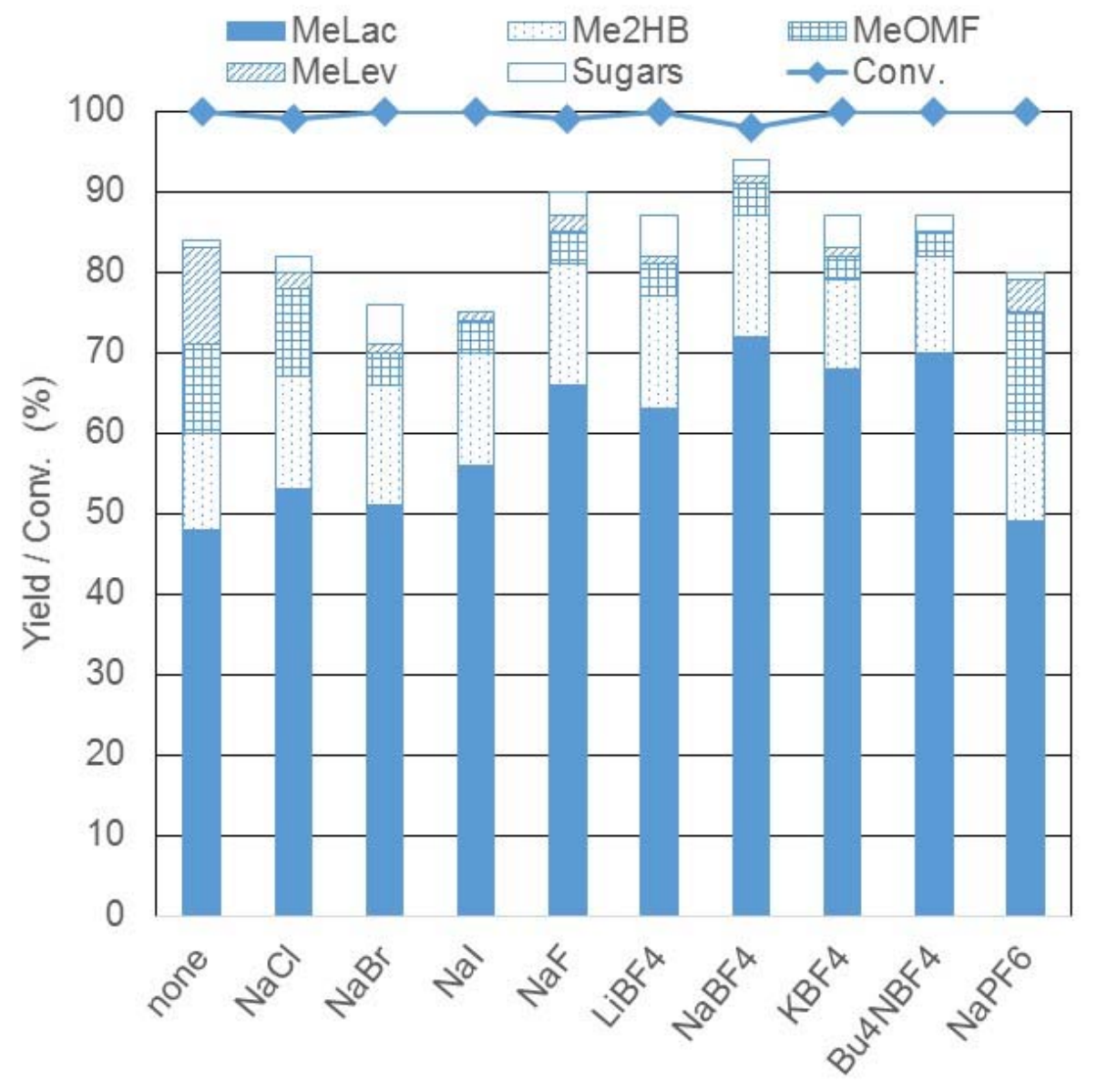


Fig. 5

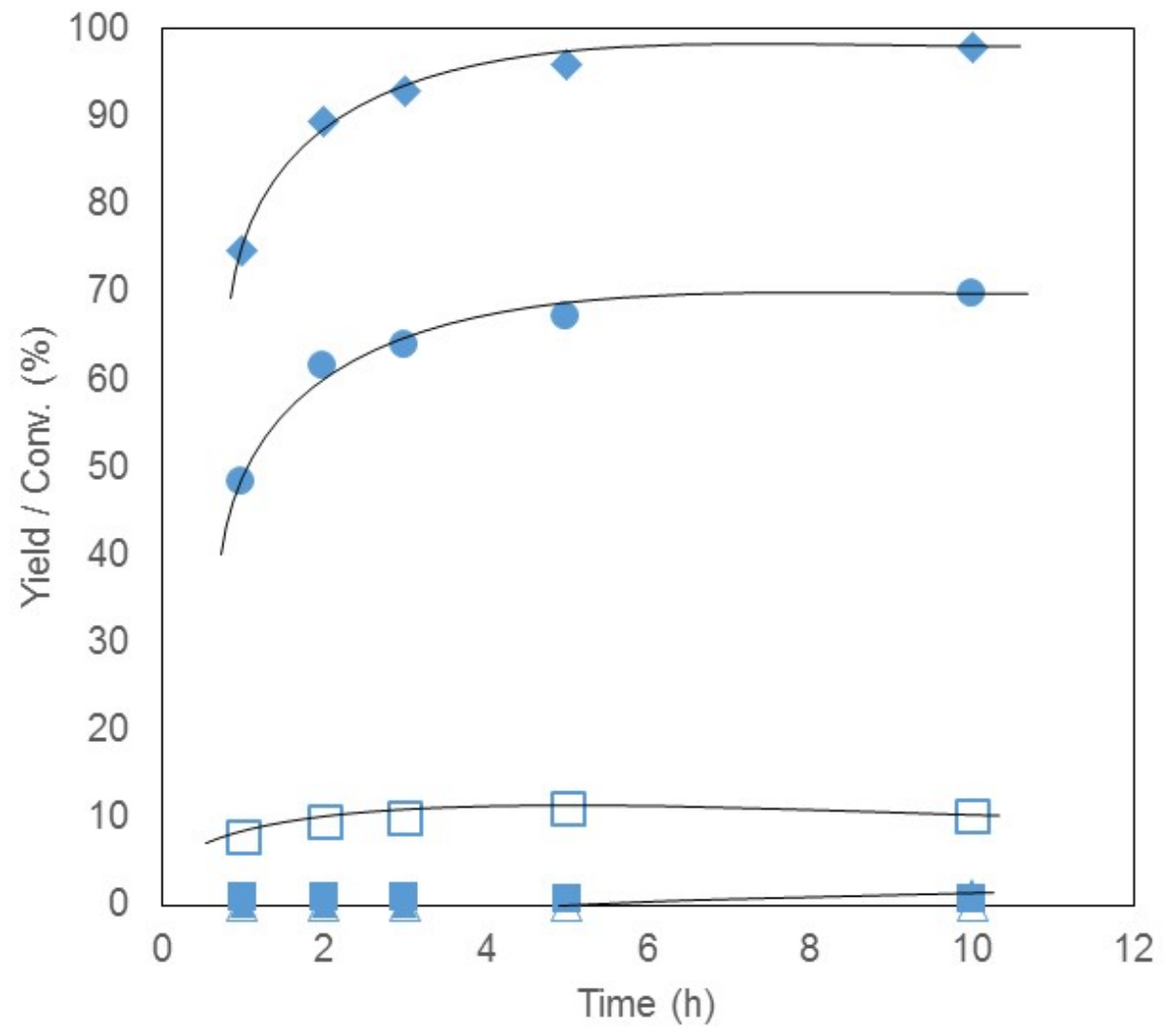


Fig. 6

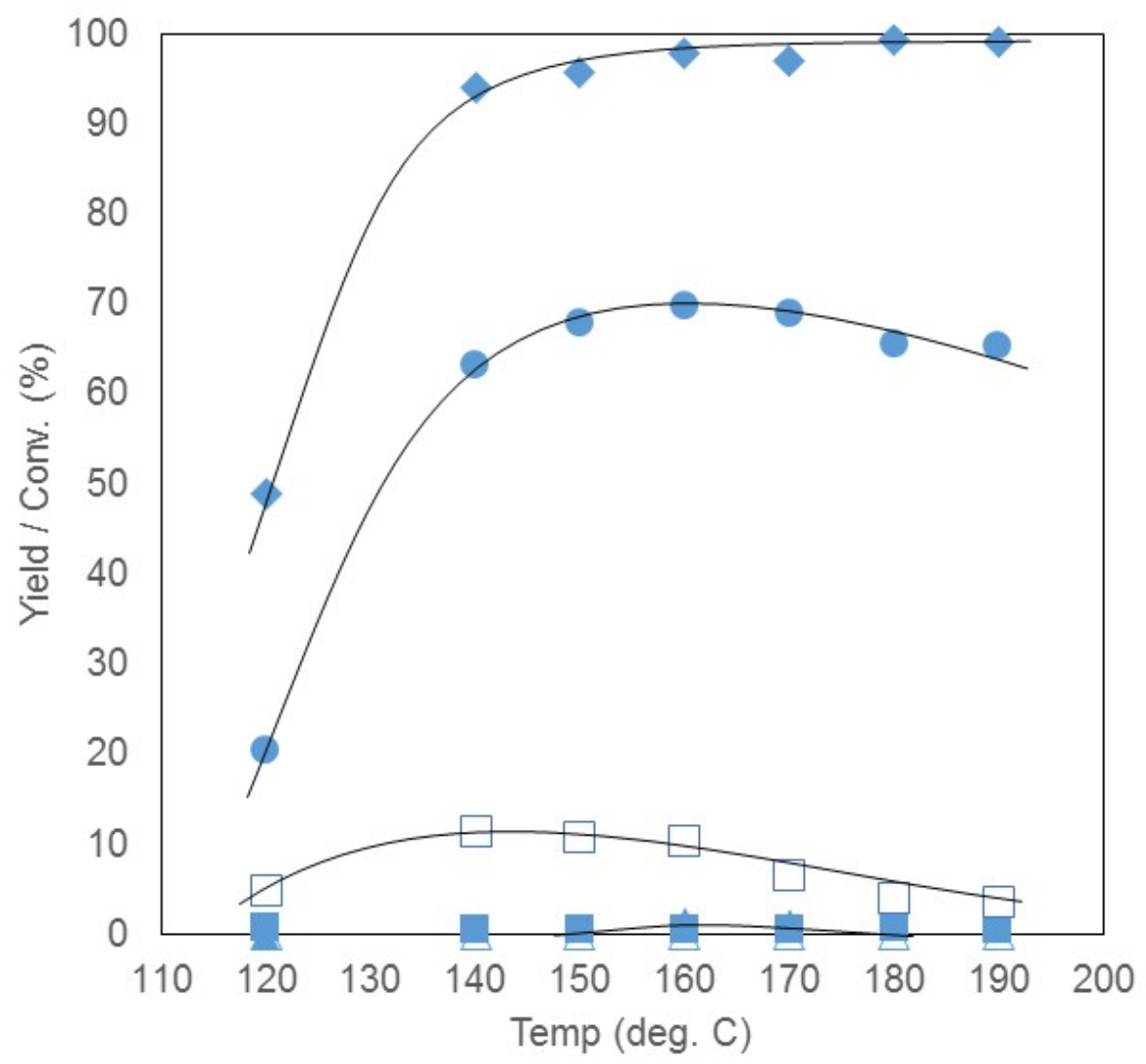


Fig. 7

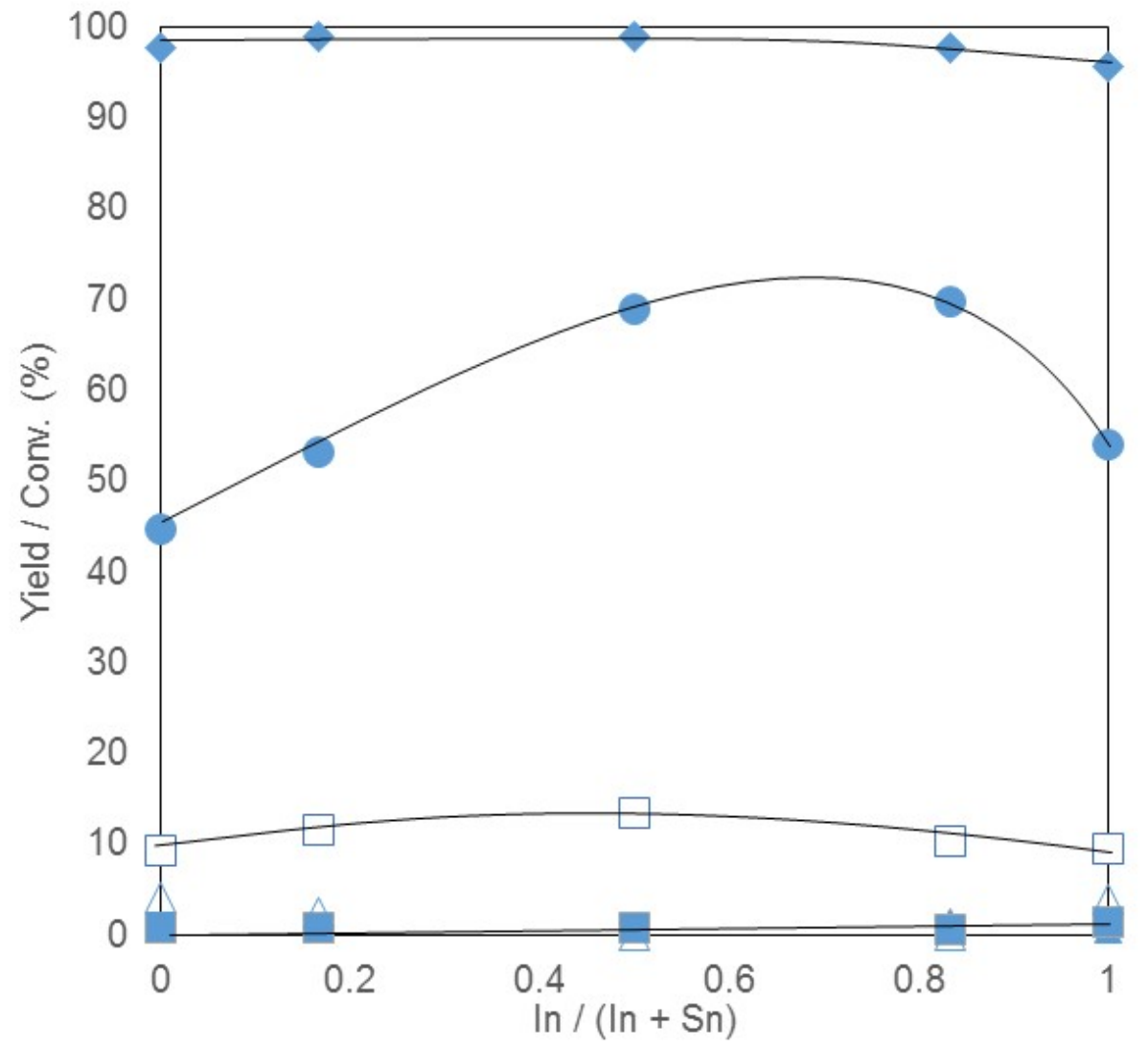


Fig. 8

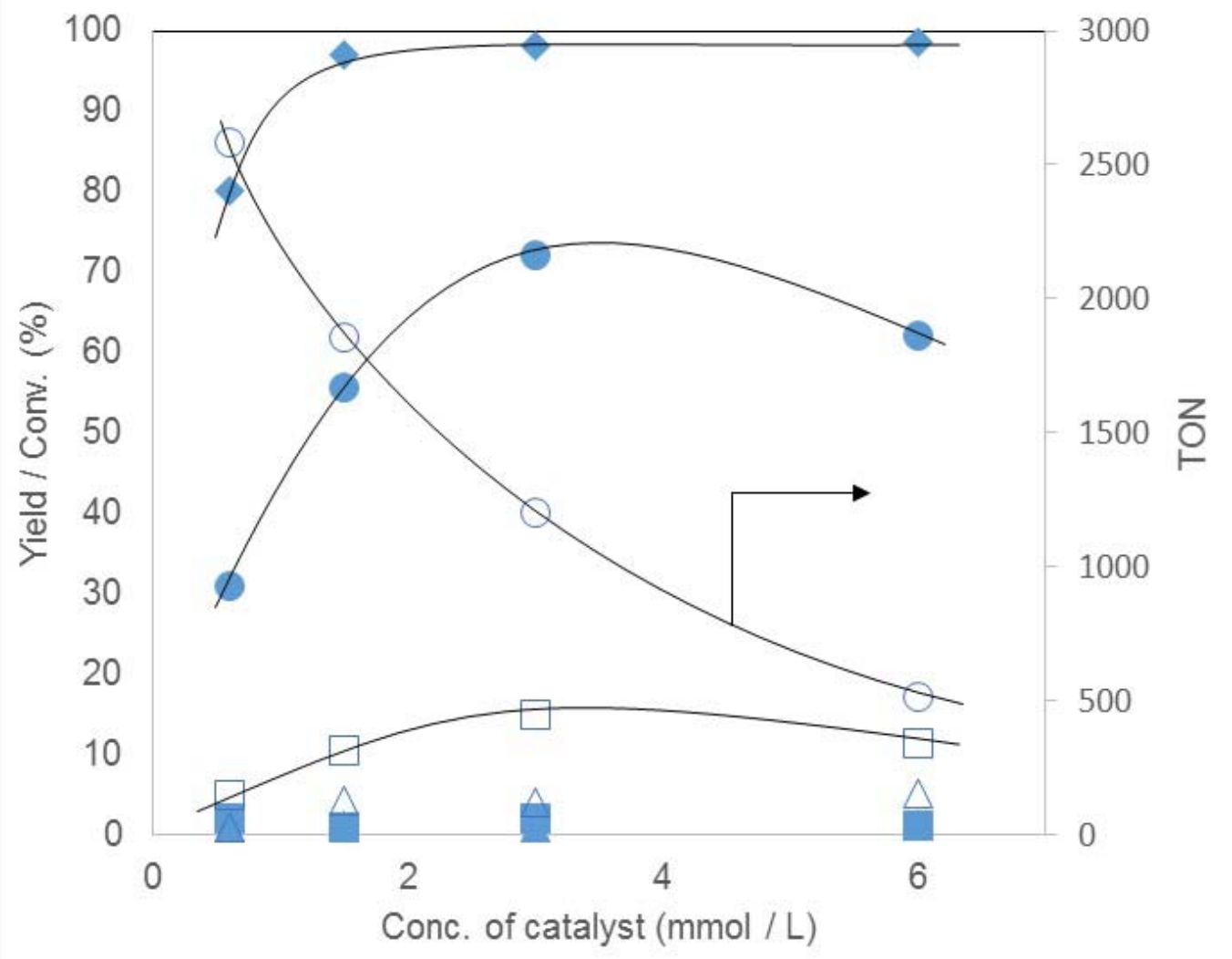


Fig. 9

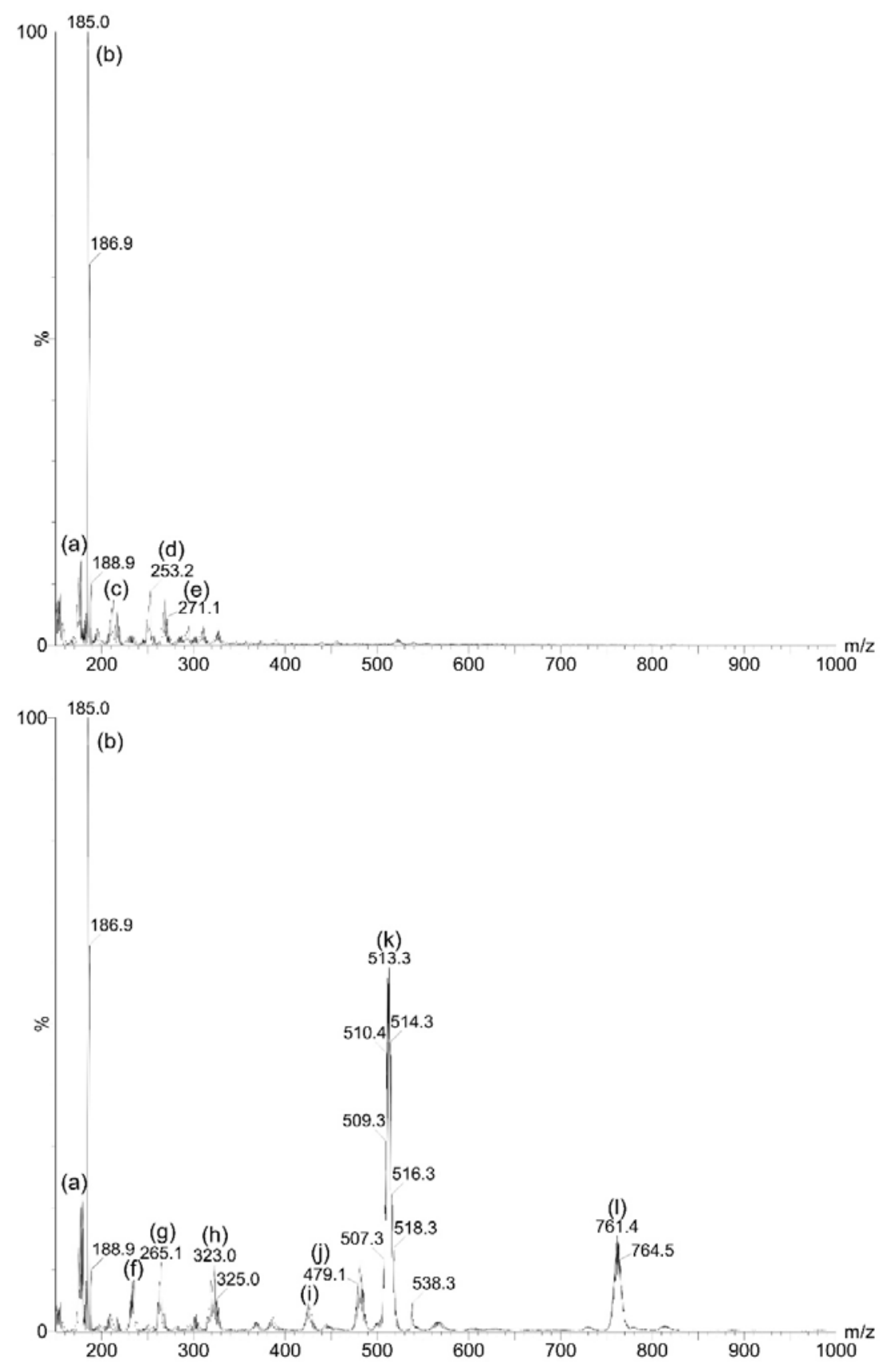


Fig. 10

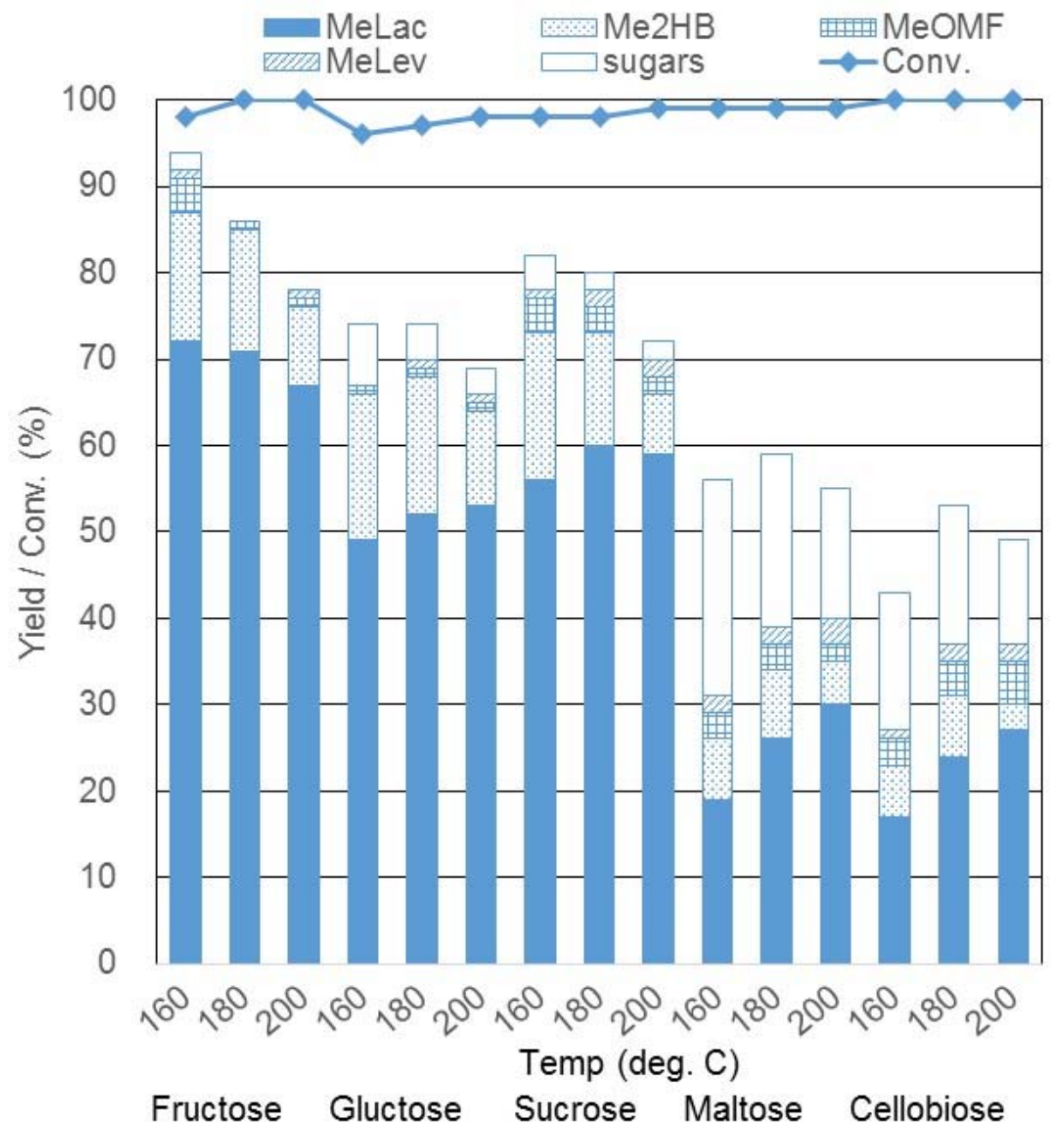




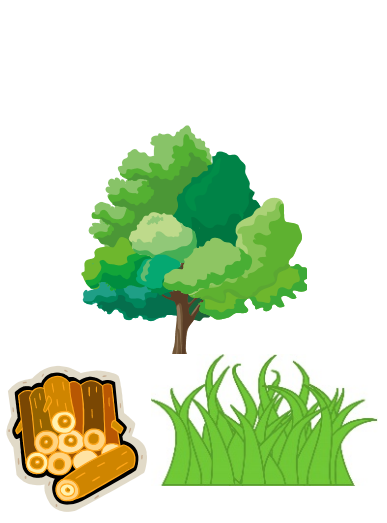

Biomass

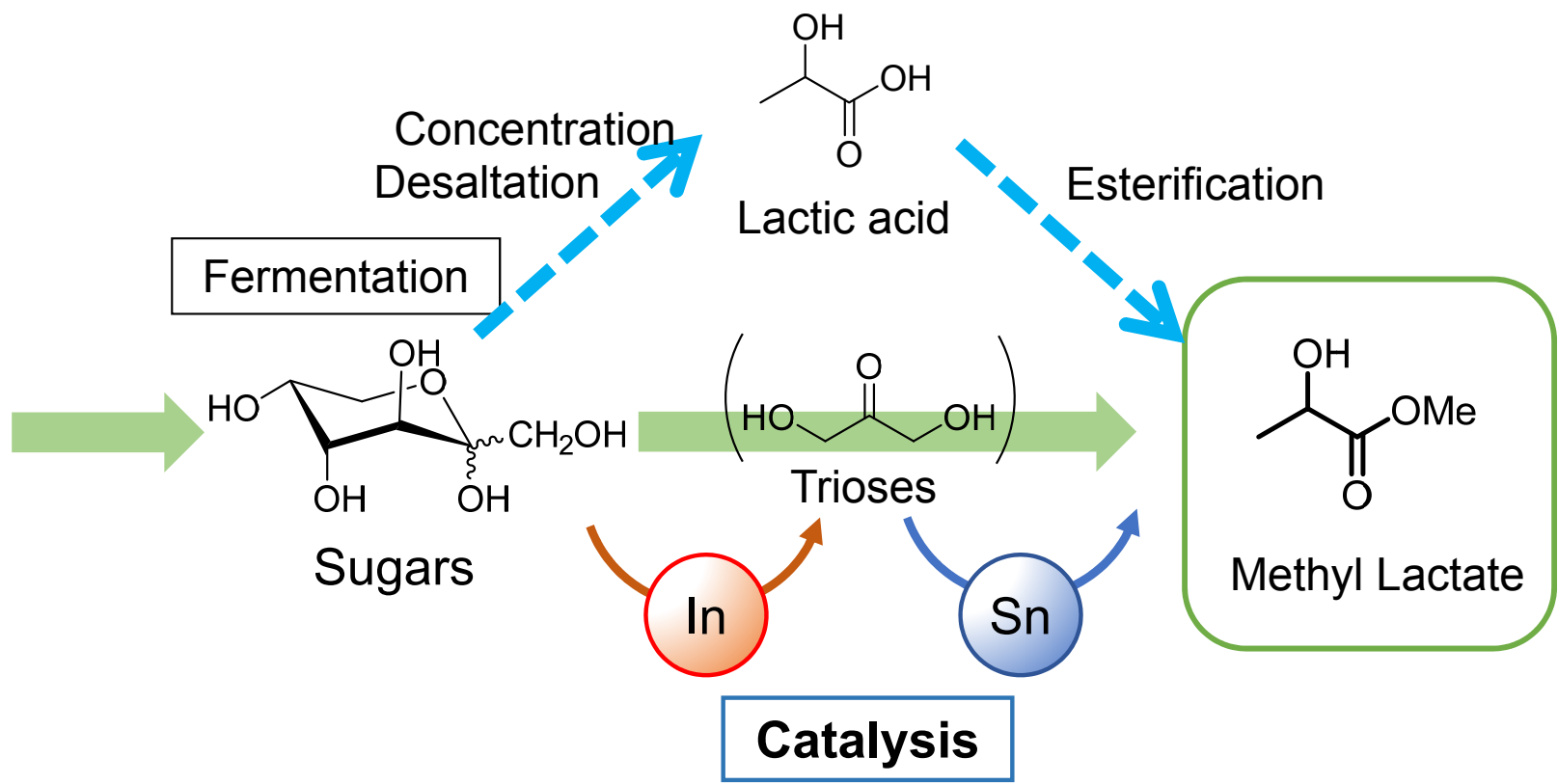

